\title{
TRATAMENTO DE APNÉIA OBSTRUTIVA DO SONO COM CIRURGIA ORTOGNÁTICA: RELATO DE CASO CLÍNICO
}

Leandro Eduardo KLÜPPEL; Alexander Tadeu SVERZUT; Márcio MORAES.

A Síndrome da Apnéia Obstrutiva do Sono (SAOS) é uma doença incapacitante associada a altos índices de morbidade. $O$ problema afeta 2 a 3\% dos homens entre 40 e 65 anos de idade e $2 \%$ das mulheres após a menopausa. Os principais sinais e sintomas da SAOS são: sono não reparador e agitado, ronco noturno, sonolência diurna, cefaléia e distúrbios comportamentais. Os efeitos da SAOS incluem o surgimento de doenças cardiovasculares que, em última instância, irão diminuir a expectativa de vida dos pacientes que porventura não receberem nenhum tipo de tratamento. Seu diagnóstico é feito com base nos achados clínicos e no exame de polissonografia. O tratamento desta condição varia de acordo com a gravidade e com a eliminação de possíveis agentes etiológicos. Geralmente os casos de apnéia grave requerem algum tipo de intervenção cirúrgica, sendo que a cirurgia ortognática ocupa lugar de destaque, tanto pela efetividade a longo prazo, quanto pela previsibilidade. $O$ objetivo deste trabalho é apresentar o caso clínico de uma paciente portadora de Síndrome da Apnéia Obstrutiva do Sono que foi submetida cirurgia ortognática. Os resultados obtidos serão discutidos e a literatura pertinente será apresentada. 